\title{
Study of Flow Problems and Those of Soil Compaction in an Agricultural Farm
}

\author{
Anis Elaoud ${ }^{* a b}$, Sayed Chehaibi ${ }^{\mathrm{a}}$, Mohamed Ben Amor ${ }^{\mathrm{b}}$ \\ ${ }^{\text {a }}$ Higher Institute of Agronomy, Chott-Mariem, 4042 Sousse, Tunisia \\ ${ }^{b}$ Natural Water Treatment Laboratory, Water Researches and Technologies Centre of Borj Cdria (CERTE), B.P. 273, Borj Cedria, 8020 Soliman, \\ Tunisia
}

Accepted 26 Feb. 2013, Available online 1March 2013, Vol.1, No.1 (March 2013)

\begin{abstract}
In agricultural land can be observed problems regarding water and soil. The problems of water flow can cause breaks in pipes, and the problems associated with soil because of the passage of vehicles and lead to compaction, engender changes in soil parameter directly affects the infiltration water and fruit yield regression plants. In this paper, we will study numerically the flow in pipes and soil compaction. So, a first part examines the phenomena of demurrage pumps; when starting a pump, the speed of the electric motor rises from zero up to the permanent regime speed. This change in regime influences the flow of the hydraulic installation and forced it to follow the starting dynamic law of the motor. Under the effect of the friction force, due to the fluid viscosity, the transient regime is dumped until reaching the normal operating conditions. In this work, we study this phenomenon and see the influence of the pump startup on the hydraulic behaviour of one dimensional flow throw a cylindrical pipe of linear elastic behaviour. The pipe is connected to constant level reservoir at the downstream end. The problem is governed by a two coupled linear hyperbolic partial differential equations which are the equations of continuity and motion. The mathematical model is solved by the method of characteristics where at the upstream end, that is, at the pump station, the boundary condition is given by the differential equation for speed change of the pump motor. A theoretical relationship is introduced to express the motor torque in terms of the time. At the downstream end the discharging reservoir is assumed to be at a constant level. The computed head and discharge time curves, caused by the starting of the pump, are plotted at some cross sections of the pipe. The results show that the evolution of the hydraulic variables is well influenced by the applied motor torque. In a second part of the numerical study of soil compaction is developed.
\end{abstract}

Keywords: Compaction soil, method of characteristics, pipe, pump start-up, transient flow.

\section{Introduction}

In recent years, the problems that exist in a farm field and touched the parts hydraulic and machinery are multiply and cause serious problems. So for the listed hydraulic and water flow, the knowledge of transient flow, which is essential to the design of many hydraulic structures, has thus advanced.

Piping systems which contain turbo-machinery require analysis that takes into account the changes occurring in the characteristics of the units as their rotational speeds change. Simple problems of flow changes in piping systems containing pump operating at constant speeds have been studied in the past (Streeter \& Wylie, 1967). If there is a rotational speed change, the rotary inertia of moving parts in the turbomachine generally should be taken into account in the simulation of this behavior. The two severe transient problems are failure of pumps power supply, when operating at maximum conditions, and the starting of pumps with unknown speed-time relation. The

*Corresponding author's Email: anis.aoud@yahoo.fr first problem have been studied graphically (Frelin, 2003) and numerically (Wylie et al., 1993).

Centrifugal pump startup is usually accomplished with the discharge valve closed, and as the pump approaches operating speed, the valve is opened slowly to minimize the transient effect of the pump startup. By placing a check valve instead of the valve or by keeping the valve open, a transient flow is provoked in the discharge pipe of the pump connected to a reservoir. A succession of pressure waves moves downstream in the discharge pipe. These waves are then reflected at the downstream end reservoir. The evolution of the transient flow is hence continued until the final steady state regime is reached.

In this study, the equations which describe transient one-dimensional flows in a cylindrical pipe caused by the movement of starting pumps impeller are described. The pumping station is connected to a discharge pipe, which in turn is connected to a reservoir and the transients are provoked by the applied motor torque. The method of characteristics is used to numerically simulate transients with given pump characteristic curves and known torquetime relation of the starting motor. 
Furthermore, also for soil compaction causes a big problem in modern agriculture. Overuse of machinery and improper management led to soil compaction. This compression increases the stress at the tire / ground contact and reduces physical soil fertility by reducing the storage and supply of water and nutrients, which leads to extra fertilizer if and increased production costs.

Thus, the feasibility of a soil reflects its ability to accept the passage of vehicles and action tools (tractors, plows, etc...) (Billot et al., 1993). The main causes of soil compaction are related to the development of mechanization (Vitlox \& Loyen, 2002). A study of experimental aspect (Elaoud \& Chehaibi, 2011), (Chehaibi et al., 2006) of soil compaction in the wheel track of the tractor used to conduct various cultural operations is carried out in Tunisia.

So, over-processing machines and intervention in the agricultural field generates a compaction which is treated numerically in the second part. This paper shows a simulation developed with software (TERRANIMO) shows the effect of a selected tractor.

\section{Materials and methods}

On hydraulic study, a numerical simulation requires the developement of mathematical equations.

\section{A. Equations weakly compressible Flow}

The governing equations for transient one-dimensional non compressible flow, in a cylindrical pipe of linear elastic behaviour according to the Hooke law (Wiggert \& Tijsseling, 2001), are a set of two coupled linear hyperbolic partial differential equations which can be adapted from the analytical model described in (Streeter \& Wylie, 1983). Applying the laws of conservation of mass and momentum yields to the following equations of continuity and motion:

$$
\begin{aligned}
& \frac{\partial H}{\partial t}+\frac{C^{2}}{g A} \frac{\partial Q}{\partial x}=0 \\
& \frac{\partial Q}{\partial t}+g A \frac{\partial H}{\partial x}+\lambda \frac{Q|Q|}{2 D A}=0
\end{aligned}
$$

where:

$\mathrm{A}$ is the pipe cross section,

$\mathrm{Q}$ is the fluid discharge,

$\mathrm{H}$ is the piezometric head,

$\lambda$ is the Darcy Weisbach friction coefficient,

$\mathrm{C}$ is the pressure wave speed,

$\mathrm{D}$ is the diameter of the pipe.

\section{B. Method of Characteristics}

The method of characteristics is often used to transform the governing partial differential equations (1) and (2) into a system of ordinary differential equations that are valid along two sets of characteristic lines (figure 1). The ordinary differential equations obtained by this method are
(Jlali et al,2005),(Fox, 1977), (HadjTaïeb \& Lili, 2000) and (HadjTaïeb \& Lili, 1999) :

$$
\begin{aligned}
& C^{+}\left\{\begin{array}{l}
\frac{1}{C} \frac{d H}{d t}+\frac{1}{g A} \frac{d Q}{d t}+J d t=0 \\
d x=C d t
\end{array}\right. \\
& C^{-}\left\{\begin{array}{l}
-\frac{1}{C} \frac{d H}{d t}+\frac{1}{g A} \frac{d Q}{d t}+J d t=0 \\
d x=-C d t
\end{array}\right.
\end{aligned}
$$$$
\text { where } J=\lambda Q|Q| /\left(2 g D A^{2}\right) \text { is the linear head loss by }
$$
unit of pipe length.

These equations can also be written under the following form:

$$
d Q \pm \frac{g S}{C} d H+g S J d t=0 \text { and } d x= \pm C d t
$$

The + is for the waves coming from the upstream while the - is for the waves coming from the downstream.

The equations (5) determine the evolution of the head pressure and the discharge according to the time and the space. They are much appropriated to be solved numerically on a microcomputer. The obtained solution constitutes a solution to the original system of the equations (1) and (2).

The transient flow is generated by a discontinuity of working (instantaneous valve closure, starting of a pump, pump failure...). This discontinuity propagates itself and the displacement is presented in the plan $(\mathrm{x}, \mathrm{t})$ by the characteristic lines. In the case of the quasi-rigid pipes, as the metallic conducts or concrete, the pressure waves propagation speed $\mathrm{C}$ is constant and the characteristic lines are right (Roberson et al.,1995).

Consider a pipe of length $\mathrm{L}$ subdivided in $\mathrm{N}$ equal reaches. If we start with known steady-state conditions at $t$ $=0$, then we know $\mathrm{Q}$ and $\mathrm{H}$ at the $\mathrm{N}+1$ sections of the conduct (Samani \& Khayatzadeh, 2002). If we specify the time interval $\Delta t=L /(N C)$, the characteristic lines from the sections $i-1$ and $i+1$ intersect at $P$, which is section $i$ (figure 1). In these conditions, the integration of the equations (5) permits to write:

$$
\begin{gathered}
Q_{P i}-Q_{i-1}+\frac{g A}{C}\left(H_{P i}-H_{i-1}\right)+g A J_{i-1} \Delta t=0 \\
Q_{P i}-Q_{i+1}-\frac{g A}{C}\left(H_{P i}-H_{i+1}\right)+g A J_{i+1} \Delta t=0
\end{gathered}
$$

The calculation of the discharge and head at any section $\mathrm{i}$ is obtained if we solve equations (8) and (9) for the $Q_{P i}$ by eliminating $H_{P i}$, thus:

$$
\begin{array}{r}
Q_{P i}=\frac{1}{2}\left[Q_{i-1}+Q_{i+1}+\frac{g A}{C}\left(H_{i-1}-H_{i+1}\right)-\right. \\
\left.A g \Delta t\left(J_{i-1}+J_{i+1}\right)\right] \\
H_{P i}=\frac{1}{2}\left[H_{i-1}+H_{i+1}+\frac{C}{g A}\left(Q_{i-1}-Q_{i+1}\right)-\right. \\
\left.C \Delta t\left(J_{i-1}-J_{i+1}\right)\right]
\end{array}
$$




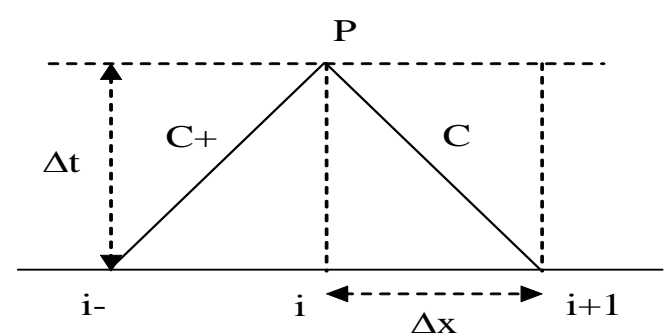

Fig.1 Characteristic lines: Regular grid

\section{Boundary Conditions}

After the first time step, the extreme points of the system begin to influence the calculation of the interior points. Thus, in order to get the solution until an elevated time level, it is necessary to introduce the appropriate boundary conditions. At either end of the pipe only one of the characteristic equations (6) or (7) is available in the two unknowns $Q_{P i}$ and $H_{P i}$.

In this study, we consider two boundary conditions, at the downstream end the reservoir has a constant level, and at the upstream end we consider the dynamic behaviour of the electric motor connected to the pump.

C.1 Constant Level Reservoir At The Down-Stream End The boundary condition is:

$H_{P N+1}=H_{0}$

In this case only equation (6) is used, and we have:

$Q_{P N+1}=Q_{N}-\frac{g A}{C}\left(H_{P N+1}-H_{N}\right)-g A J_{N} \Delta t$

\section{C.2 Pump Start-up at The-Upstream End}

When starting a centrifugal pump, a transient flow is provoked in the discharge pipe connected to the constant level reservoir. A check valve, placed on the discharge side of the pump, permits flow in the positive direction only. It is assumed that the check valve opens instantaneously when the pump has developed enough head to exceed the initial static head on the downstream side of the valve.

In this case the electrical load required of the motor at start up is less than normal.

To analyze the boundary condition at the upstream end it is necessary to have the motor torque-time data from the motor manufacturer, and then use the complete torque equation:

$T_{\text {motor }}-T_{\text {resistant }}=I \frac{d \omega}{d t}$

in which $\mathrm{I}$ is the moment of inertia of rotating parts including the liquid within the impeller, $T_{\text {resistant }}$ is the resistant torque which depends on the rotational speed $\omega$ and the discharge Q (Schulhof, 1972):

$T_{\text {resistant }}=a_{1} \omega^{2}+a_{2} \omega Q$
Equation (12) gives the speed change of the pump due to the applied motor torque.

Beginning at any initial condition the left-hand side of the equation (13) must be positive to accelerate the pump to normal operating conditions. That is the motor torque must exceed the pump resistive torque over the entire speed range during pump start-up.

Parameter and $\mathrm{T}_{0}$ is the motor torque at the permanent regime. For this regime, the motor speed is constant, that means:

$\frac{d \omega}{d t}=0$

In that case, the equation (12) permits to calculate the motor torque $\mathrm{T}_{0}$ of the permanent regime:

$T_{\text {motor }}=T_{0}=T_{\text {resistant }}$

For a given $\omega$, the characteristics of the pump, such as the piezometric head, the efficiency and the resistant torque, are well known as functions of the discharge Q.

If we consider an initial instant ti and a final instant $t f$, and we assume during the interval of time $t_{f}-t_{i}$, the motor torque and the discharge remain unchanged, we can write:

$$
\int_{\omega_{i}}^{\omega_{f}} \frac{d \omega}{a_{1} \omega^{2}+a_{2} \omega Q_{i}+T_{\text {motor }}}=-\frac{1}{I} \int_{t_{i}}^{t_{f}} d t
$$

The integration of this equation gives:

$\omega_{f}=\frac{\omega_{1} e^{\left[\left(t_{f}-t_{i}\right) /(A I)\right]}-B \omega_{2}}{e^{\left[\left(t_{f}-t_{i}\right) /(A I)\right]}-B}$

where:

$$
\begin{aligned}
& \omega_{1}=\frac{-a_{2} Q+\sqrt{\left(a_{2} Q\right)^{2}-4 a_{1} T_{\text {moto }}}}{2 a_{1}}, \\
& \omega_{2}=\frac{-a_{2} Q-\sqrt{\left(a_{2} Q\right)^{2}-4 a_{1} T_{\text {moto }}}}{2 a_{1}}, \\
& A=\frac{1}{a_{1}\left(\omega_{1}-\omega_{2}\right)}, \quad B=\frac{\omega_{i}-\omega_{1}}{\omega_{i}-\omega_{2}} .
\end{aligned}
$$

Once we get $\omega_{f}$, and by using the pump characteristic equation:

$$
H_{P 1}=a_{0}\left(\frac{\omega_{f}}{\omega_{0}}\right)^{2}-b_{0} Q_{P 1}^{2}
$$

and the compatibility equation (7) written as:

$H_{P 1}=\frac{C}{g A} Q_{2}-H_{2}-J_{2} \Delta x+\frac{C}{g A} Q_{P 1}=C_{1}+C_{2} Q_{P 1}$

we can calculate the discharge $Q_{P 1}$ by resolving the quadratic equation:

$$
b_{0} Q_{P 1}^{2}+C_{2} Q_{P 1}+C_{1}-a_{0}\left(\frac{\omega_{f}}{\omega_{0}}\right)^{2}=0
$$

If the root is negative we take $Q_{P 1}=0$. The piezometric head at the instant $t_{f}$ can be obtained from equation (19). The subscript 0 refers to the final regime conditions under the motor torque $\mathrm{T}_{0}$. On soil compaction causing a 
problem for the plant and asphyxia causes several other problems on runoff water and other.

\section{Simulation method to study soil compaction}

A platform used to evaluate compaction related to expenses in the soil profile of agricultural land. The research processes, outcomes and gaps related to soilmachine components including evaluation of the compaction.

So the goal of our research is to study the structural changes of soil produced by the weight of the gear used in the field.

The evolution of the state of soil compaction has been followed by the theoretical behavior of the soil after passing gear.

\section{E. Presentation of the parameters of tractors}

Measurements will be performed initially to characterize soil conditions and parameters of tractors. In this context, these tractors perform the passage of soil containing $15 \%$ clay, $75 \%$ sand and $10 \%$ silt.

The first tractor $170 \mathrm{cv}$ - weight $3900 \mathrm{Kg}$ rear axle and front axle $2600 \mathrm{~kg}$.

The second $90 \mathrm{cv}$ tractor - weight $2850 \mathrm{Kg}$ rear axle and $1550 \mathrm{Kg}$ front axle.

Table 1. Characterization of the rear wheels

\begin{tabular}{|l|l|l|}
\hline Parameters & Tractor 1 & Tractor 2 \\
\hline Tyre Type & driving wheel & driving wheel \\
\hline Constructor & Michelin & Michelin \\
\hline Tire model & Omnibib & Omnibib \\
\hline Tire size & $580 / 70 \mathrm{R} 38$ & $520 / 70 \mathrm{R} 34$ \\
\hline Wheel load & 1950 & 1425 \\
\hline Inflation pressure $[\mathrm{bar}]$ & 2,0 & 2,0 \\
\hline
\end{tabular}

Table 2. Characterization of the front wheels

\begin{tabular}{|l|l|l|}
\hline Parameters & Tractor 1 & Tractor 2 \\
\hline Tyre Type & driving wheel & driving wheel \\
\hline Constructor & Michelin & Michelin \\
\hline Tire model & Omnibib & Omnibib \\
\hline Tire size & $480 / 70 \mathrm{R} 24$ & $420 / 70 \mathrm{R} 24$ \\
\hline Wheel load & 1300 & 775 \\
\hline Inflation pressure [bar] & 0,8 & 0,8 \\
\hline
\end{tabular}

\section{Result and discussion}

To study the transient regime due to the pump startup, we consider the hydraulic installation (figure 2) supplied by an electrical motor pump at the upstream end. At the discharge side of the pump a security check valve is installed. The fluid is pumped through a cylindrical pipe, with $700 \mathrm{~m}$ of long and $0.7 \mathrm{~m}$ of internal diameter, to supply a constant level reservoir placed at the downstream end.
The method of characteristics is used to numerically simulate transients caused by the movement of the pump impeller. The characteristics curves of the pump and the torque-time relation of the starting motor are given by the manufacturer for constant rotational speeds.

Figures 3 and 4 show these curves for a pump of a speed $\omega_{0}=1500 \mathrm{rpm}$, which represents the final permanent regime.

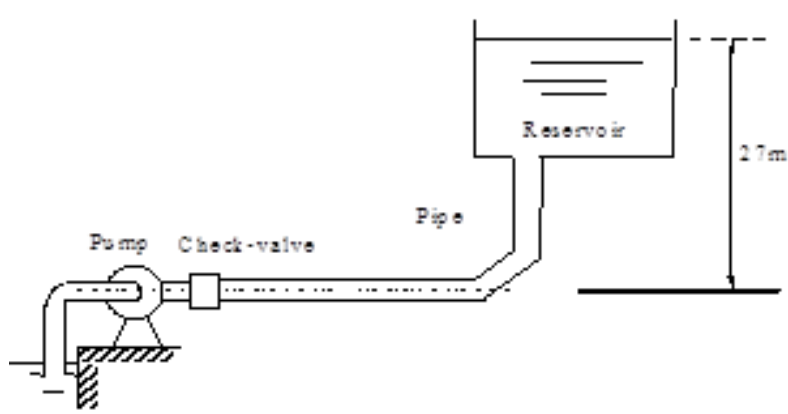

Fig. 2 Hydraulic installation

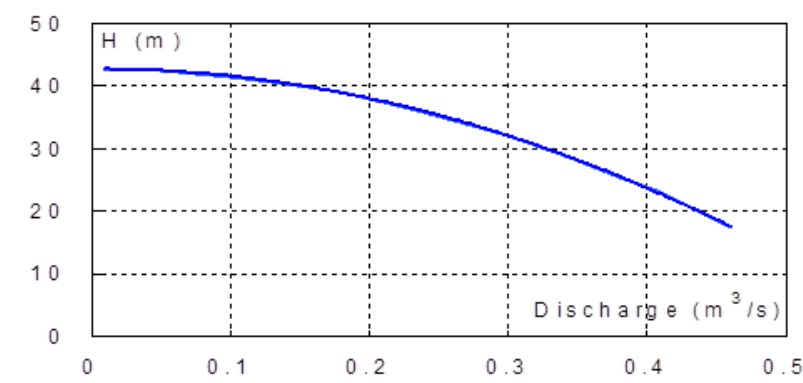

Fig.3 Pump characteristic curve at $1500 \mathrm{rpm}$

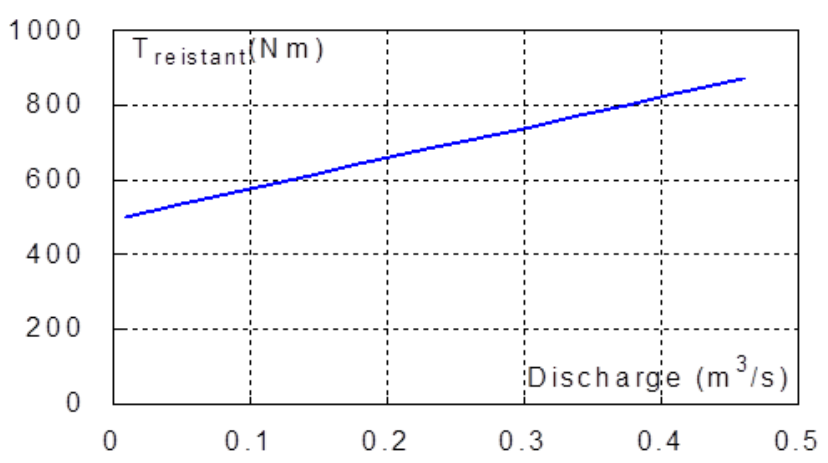

Fig.4 Resistant torque of the pump at $1500 \mathrm{rpm}$

Once the characteristics of the pump are known, it is easy to determine the constants a1 and a 2 in equation (13) and constant $\mathrm{a} 0$ and $\mathrm{b} 0$ in equation (19). We have $\mathrm{a} 1=0.02$, $\mathrm{a} 2$ $=5.236, \mathrm{a} 0=42.8$ and $\mathrm{b} 0=120$. The motor torque $\mathrm{T} 0$ of the final permanent regime is equal to $740 \mathrm{Nm}$.

Figures 5-a, 5-b, 5-c and 5-d show for each value of Motor torque in time caused by the starting of the pump. The transients are provoked by the applied motor. The permanent regime is equal to $740 \mathrm{Nm}$ (fig 5-a), about $6 \mathrm{~s}$ (fig 5-b) then 60s (fig 5-d). 
Figures 6-a, 6-b, 6-c and 6-d show for each value of the transient discharge time curves at some cross sections of the pipe caused by the starting of the pump. The transients are provoked by the applied motor.

The discharge is stabilized at the value $0.3 \mathrm{~m} 3 / \mathrm{s}$ for a temperature which increases the engine torque and spreading over fluctuations appears. Figures 7-a, 7-b, 7-c and 7-d show for each value of the transient heads time curves at some cross sections of the pipe caused by the starting of the pump. The transients are provoked by the applied motor. And the stabilization of the load in the pipe is between 27 and $32 \mathrm{~m}$ for each spreading the temperature section. So, damping of engine torque, the stabilization takes longer and a temperature fluctuation appears.

The figures 8-a, 8b, 8-c and 8-d shows the trajectories HQ- plane for different values of the damping parameter (Li, 1966). We can see that for the values of the damping parameter less than 0.2 , there is closed trajectories around a singular point corresponding to the final steady state regime.

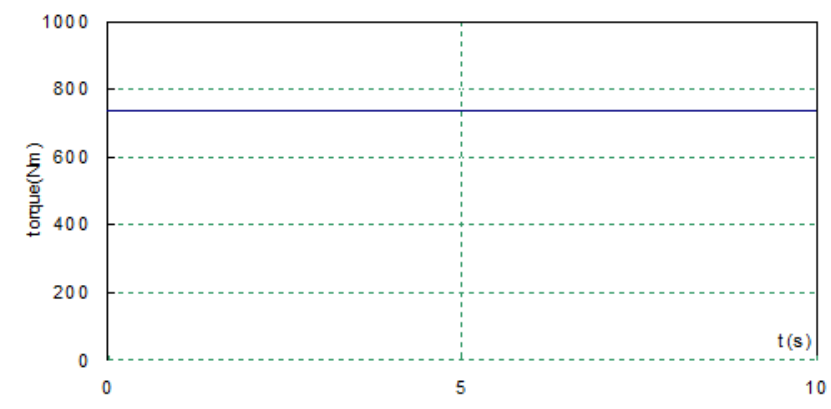

Fig 6-a Motor torque.

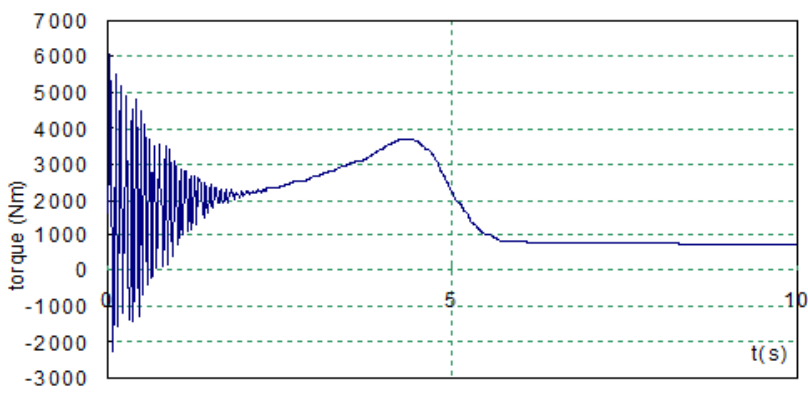

Fig 6-b Motor torque.

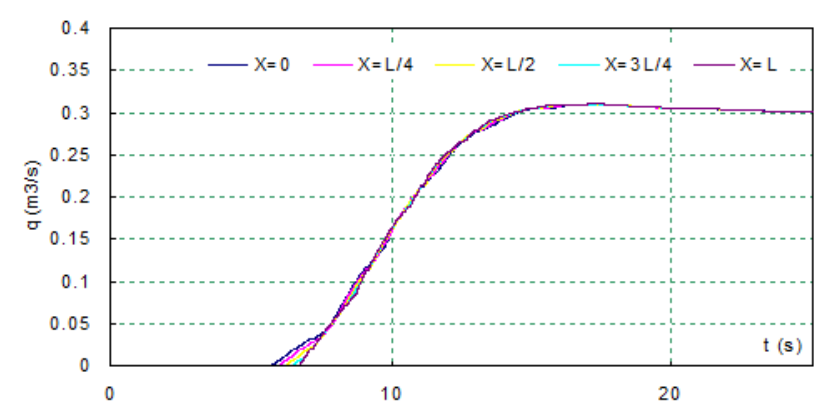

Fig 7-a Transient discharges at selected sections of the pipe caused by the pump starting at $\mathrm{x}=0$.

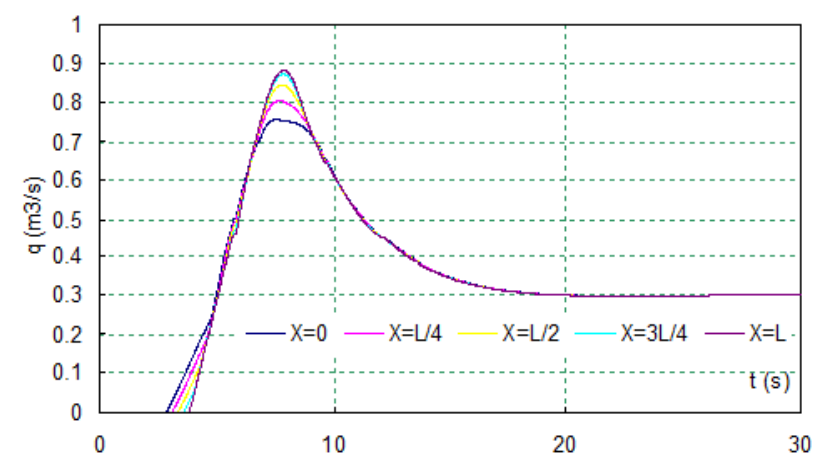

Fig 7-b Transient discharges at selected sections of the pipe caused by the pump starting at $\mathrm{x}=0$.

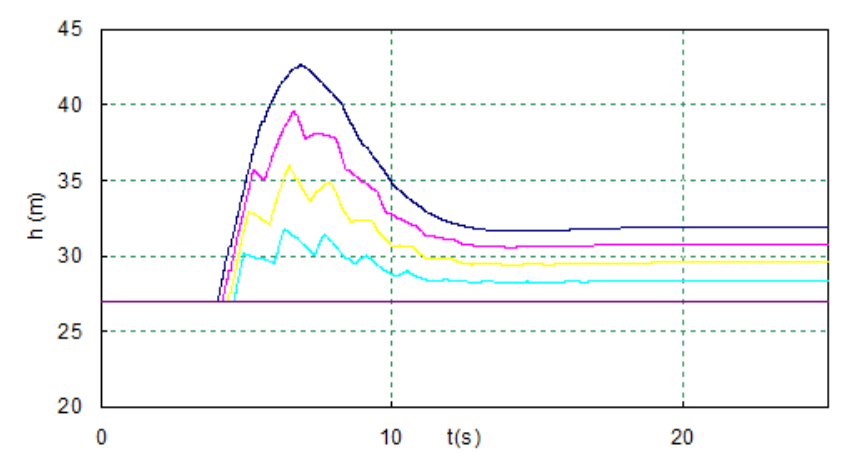

Fig 8-a Transient heads at selected sections of the pipe caused by the pump starting at $\mathrm{x}=0$.

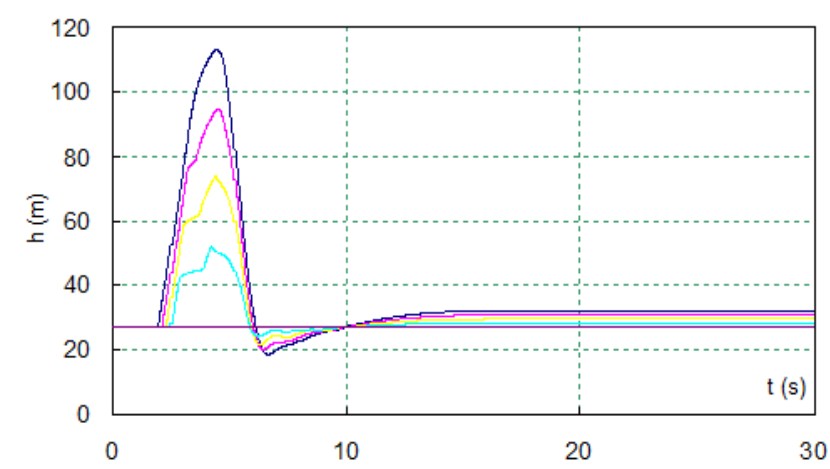

Fig 8-b Transient heads at selected sections of the pipe caused by the pump starting at $\mathrm{x}=0$.

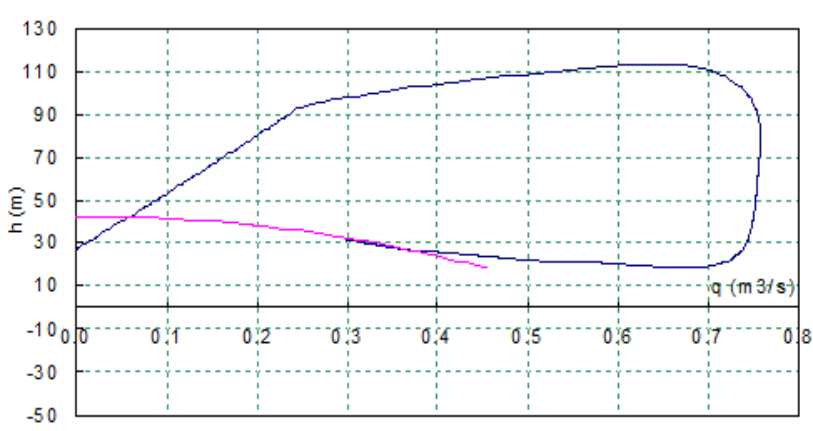

Fig 9-b Trajectories in HQ- plane of the transients at $\mathrm{x}=0$. 


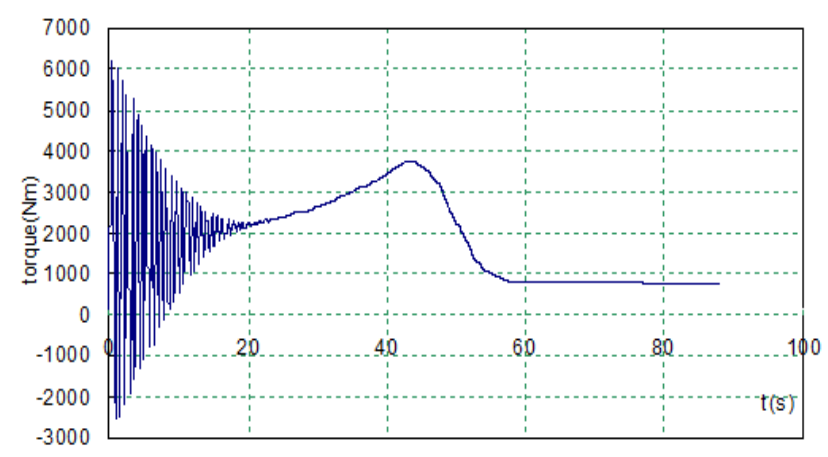

Fig 6-c Motor torque.

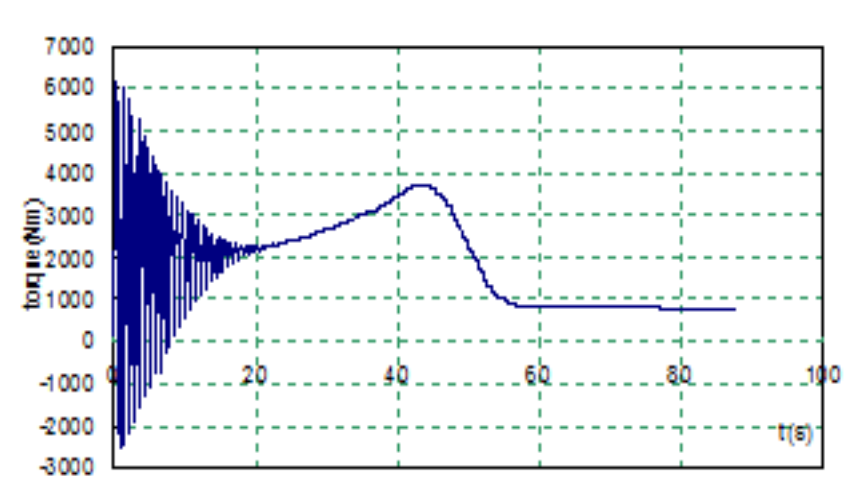

Fig 6-d Motor torque.

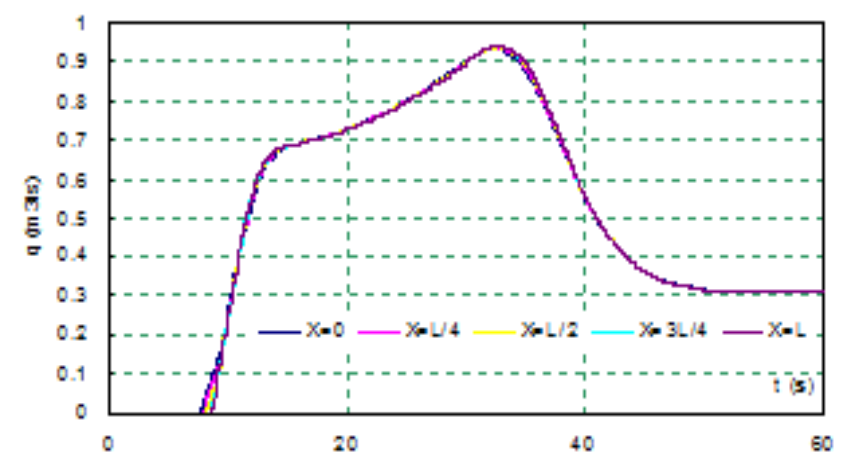

Fig 7-c Transient discharges at selected sections of the pipe caused by the pump starting at $\mathrm{x}=0$.

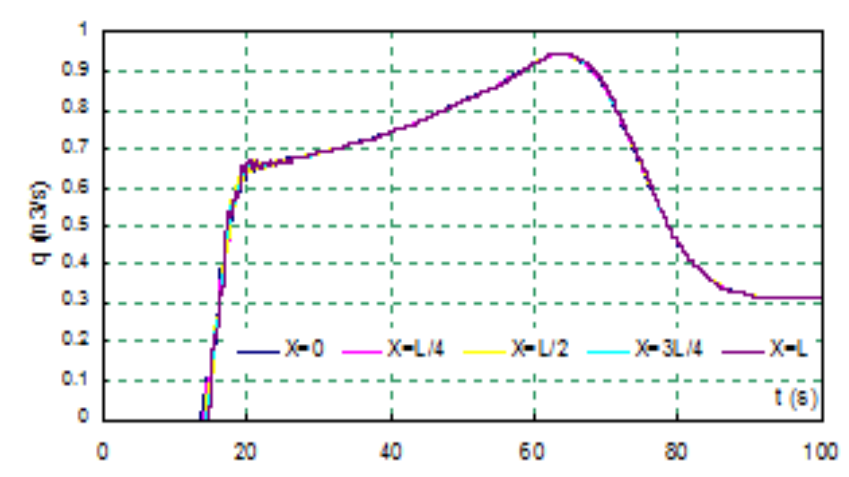

Fig 7-d Transient discharges at selected sections of the pipe caused by the pump starting at $\mathrm{x}=0$.

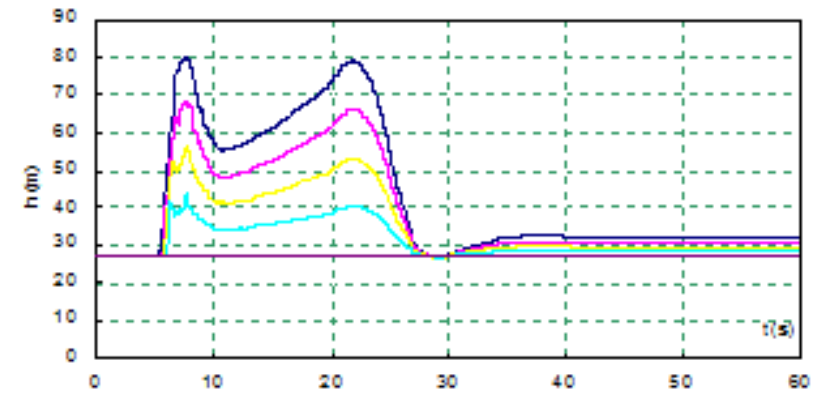

Fig 8-cTransient heads at selected sections of the pipe caused by the pump starting at $\mathrm{x}=0$.

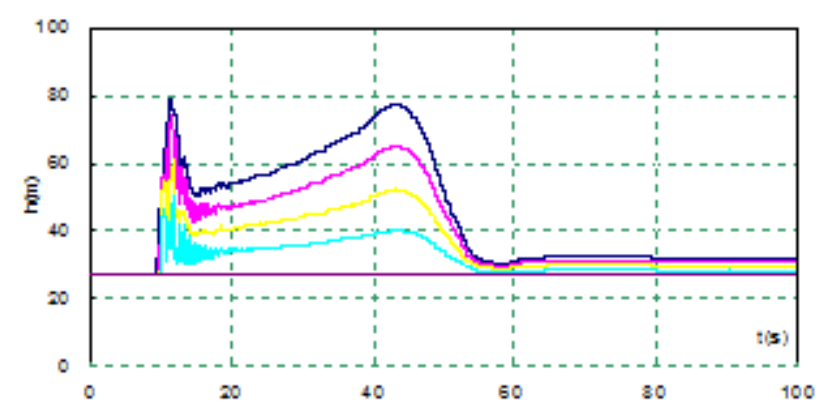

Fig 8-d Transient heads at selected sections of the pipe caused by the pump starting at $\mathrm{x}=0$.

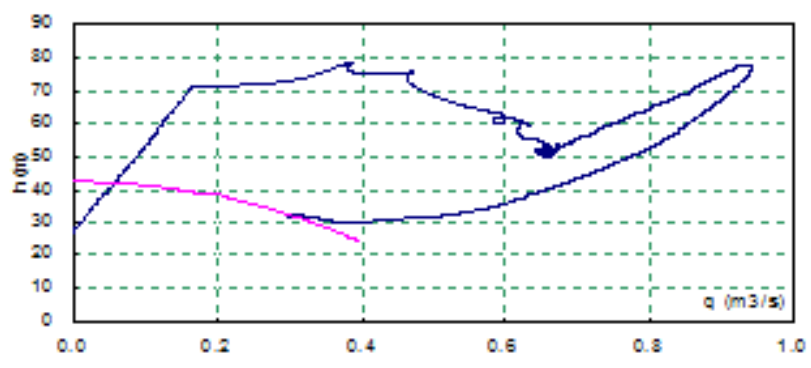

Fig 9-c Trajectories in HQ- plane of the transients at $\mathrm{x}=0$.

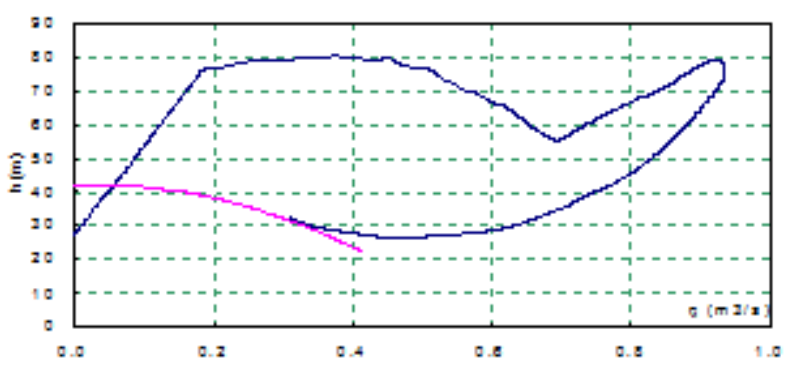

Fig 9-d Trajectories in HQ- plane of the transients at $x$ $=0$.

Of this section is to simulate the footprint of ground contact wheel / two tractor mass $6500 \mathrm{~kg}$ respectively and $4400 \mathrm{~kg}$ when passing them.

Examination of the results of the theoretical effect of the passage of the first tractor (fig 10 and fig 11) shows a slowdown serious enough at the rear wheel because of the constraints that exceed $100 \mathrm{kPa}$. This compaction may affect constraints affecting the basement depth of about 50 $\mathrm{cm}$. 
And reviewing the results of Figures 12 and 13 shows the theoretical settlement after the passage of the second tractor. This decrease is less severe because the stresses at the rear wheel do not exceed $50 \mathrm{kPa}$. Undergoes compaction affects stresses in the basement depth of about $25 \mathrm{~cm}$.

Indeed, there is a more intense compaction (increased resistance to penetration) during the passage of the vehicle heavier. Also, the increased weight of the vehicle of $32 \%$ ( $27 \%$ on the rear axle) produces an increase in stresses at tire / ground contact of approximately $100 \%$. Thus that show for each value of motor torque in time, the stabilization takes a time longer and more fluctuations appears.

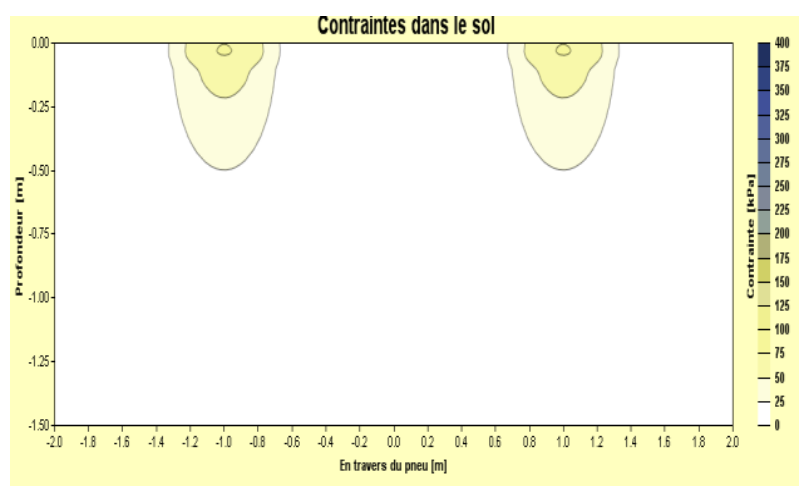

Fig.10. Stress in the soil conducted by the tractor 1

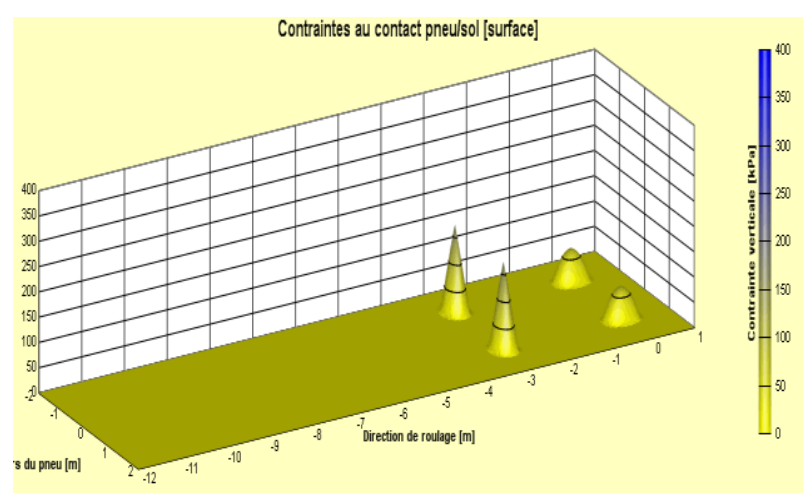

Fig.11. Stress at tire/ground contact in 3D (Tractor 1)

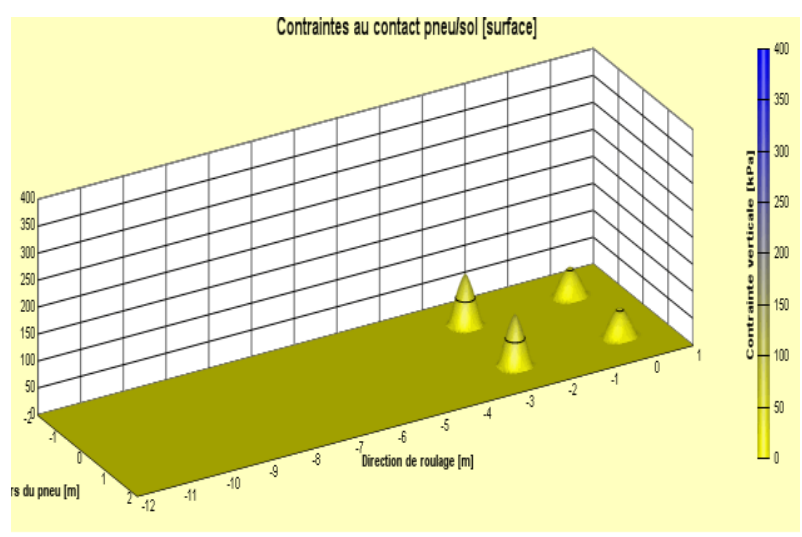

Fig.12. Stress in the soil conducted by the tractor 2

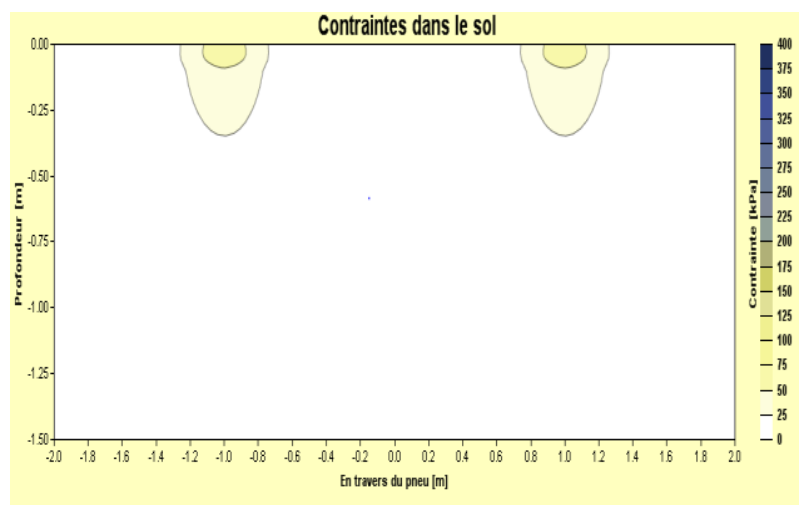

Fig.13. Stress at tire/ground contact in 3D (Tractor 2)

\section{Conclusion}

In this study, the numerical solution of the transient flows in rigid pipelines caused by starting pumps has been presented. This problem is governed by coupled two linear partial differential equations of the hyperbolic type. The numerical method employed is the method of characteristics. In order to completely see the effect of the pump startup until reaching the steady state regime, we have considered a check-valve on the discharge side of the pump. This valve permits flow in the positive direction only. And discharge of the flow plotted at some cross sections of the pipe.

The study of torques permanent in rapid and slow stabilization shows that they affect the heads and discharge during a pump start. If it accelerates the stabilization torque, it can cause an excessive increase in pressure can sometimes burst the pipe. This increase stabilizes quickly and proportionately to the stabilization of torque. Thus, the numerical study that we conducted on the effect of the mass of the vehicle, showed the influence of weight (on the rear axle and the front axle) on the degree of soil compaction. Indeed, the increase in weight of the vehicle of $32 \%$ ( $27 \%$ on the rear axle) produces an increase in stresses at tire/ground contact of approximately $100 \%$.

\section{References}

Billot, J.F. Aubineau, M. \& Autelet, R. (1993). "Les matériels de travail du sol", semis et plantation, Paris: CEMAGREF/ITCF/TEC \& DOC, , 384p.

Chehaibi, S. Hamza, E. Pieters J. \& Verschoore, R. (2006) "Analyse comparative du tassement du sol occasionné par les passages de deux types de tracteurs". Annales de l'INRGREF, $\mathrm{n}^{\circ} 8,157-170$.

Elaoud, A. Chehaibi,S. (2011). "Soil compaction due to tractor traffic", Journal of Failure Analysis and Prevention, JFAPDOI 10.1007/s11668-011-9479-3, p539-545.

Fox, J.A. (1977). "Hydraulic Analysis of Unsteady Flow in Pipe Networks", The Mac Millan Press LTD., London

Frelin, M. (2003). "Coup de bélier", Les techniques de l’Ingénieur, Volume BM 4176, pp. 1-27A.

Hadj-Taïeb, E. Lili, T. (1999). "The Numerical Solution of the Tansient Two-Phase Flow in Rigid Pipelines", International 
Journal For Numerical Methods in Fluids, 29 pp. 501-514, John Wiley \& Sons, Ltd.

Hadj-Taïeb, E. Lili, T. (2000). "Validation of hyperbolic model for water-hammer in deformables pipes", ASME, Journal of fluids engineering, vol. 122, pp. 57-64.

Jlali, A. Hadj-Taib, E. Thirriot, C. (2005). "Algorithme simplifié de calcul de phénomènes de propagation d'ondes dans les systèmes de conduites avec embranchement", la Houille Blanche, Revue Internationale de L'eau, $\mathrm{N}^{\circ} 1$, pp. 81-89.

Li, W.H. (1966). "Differential equations of hyperbolic transients, dispersion, and ground water flow", Mathematical methods in Water resources, Prentice-Hall, Inc. Englewood Cliffs, N.J.

Roberson, J.A. Cassidy, J.J. Chandhry, M.H. (1995). "Hydraulic engineering", John Wiley \& sons.

Samani, H.M. Khayatzadeh, V. A. (2002). "Transient flow in pipe networks", Journal of Hydraulic Research, Vol. 40, No 5, pp. 637-644.
Schulhof, P. (1991). "Les stations de pompage d'eau", Lavoisier$T e c \& D o c$, Paris.

Streeter, V.L. Wylie, E.B. (1967). "Hydraulic transients", McGraw-Hill Book Company, New York

Streeter, V.L. Wylie, E.B. (1983). "Hydraulic transients", F.E.B. Press, Ann Arbor.

Vitlox, O. \& Loyen, S. (2002). "Conséquences de la mécanisation sur la compaction du sol et l'infiltration de l'eau", Compte rendu de la journée d'étude: Erosion hydrique et coulées boueuses en Région Wallonne, pp. 4558.

Wiggert, D.C. Tijsseling, A.S. (2001). "Fluid transients and fluid-structure interaction in flexible liquid-filled piping", ASME, Applied Mechanics Reviews, Vol. 54, pp. 455-481

Wylie, E.B. Streeter, V.L, Suo L. (1993) "Fluid transients in Systems", Prentice Hall, Englewood Cliffs, N.J. 